\title{
Validation of MRI in the Assessment of Tophaceous Gout: An Imaging Panegyric
}

\author{
Khizer Razak ${ }^{1}$, Surbhi Gupta ${ }^{2}$, G.L.Meena ${ }^{3^{*}}$ \\ ${ }^{1,2,3}$ Department of Radio-diagnosis, S. P. Medical college, Bikaner, Rajasthan
}

Received: May 15, 2017; Accepted: May 22, 2017; Published: December 30, 2017

*Corresponding author: Dr. G. L. Meena, Senior Professor \& Head, Dept. of Radio-diagnosis, Sardar Patel Medical College, Bikaner, Rajasthan-334003; Email: meenabkn@yahoo.co.in

\section{Abstract}

Aims \& Objectives: Validation of MRI as a method of diagnosis and measurement of gouty tophi.

Materials and Methods: We prospectively obtained 41 knee MRI studies of 19 patients with tophaceous gout: 28 at the beginning [ 3 of them bilateral] and 13 during the follow-up [ 1 of them bilateral] after receiving hypouricenmiante treatment.

All the patients were men with a mean age at the first resonance of 56 years and all of them were diagnosed with gout through the direct visualization of Monosodium Urate crystals [MSU] in the synovial fluid of the knees.

Conclusion: The MRI of the knee in patients with tophaceous gout shows good agreement for the detection of tophi and a good intraclass correlation both intra and interobserver for its measurement when considering the maximum diameters.

Keywords: Gout; Imaging; MRI; Tophi; Knee; Urate

\section{Introduction}

Magnetic Resonance Imaging [MRI] allows assessing the presence of joint deposits of Monosodium Urate [MSU] and bone erosions in patients with tophaceous gout. In addition, it allows the detection of associated structural lesions, such as meniscus or ligament pathology, which can be confusing with chronic symptoms associated with urate deposition [1,2]. On the other hand, MRI after intravenous infusion of gadolinium facilitates the study of inflammatory changes of the synovial membrane [3].

MRI is especially useful in patients with solitary tophi, without joint disease, who can pose a differential diagnosis with neoplastic processes, pigmented villonodular synovitis, and granulomatous diseases such as mycosis or tuberculosis, or in tophi with an important inflammatory reaction that can mimic septic arthritis or an osteomyelitis [1-6].

The tophi are visualized as masses located in soft parts of medium-low variable signal, heterogeneous in $\mathrm{T} 2$ sequences, and typically hypointense and homogeneous in T1 sequences [2-6]. After administration of intravenous contrast, an enhancement can be visualized around the nodular image, called corona, due to the increase in vascularization associated with the granulation tissue [7].
The localization of the tophi is variable, so intratendinous, intraligamentous, intrasynovial, intraosseous or extraligamentous paraarticular tophi can be observed. In addition, in general they tend to be deposited following the fascial and compartmental planes and not radially [8-11].

As a criterion for monitoring the response to treatment, the visualization and measurement of tophi is used by imaging techniques, which avoids the repeated aspiration of a joint with previous deposits of urate [12].

Excessive uric acid accumulation contributes to hyperuricemia [defined as an elevated serum uric acid (sUA)] level above $7 \mathrm{mg} /$ $\mathrm{dl}$ in men and above $6 \mathrm{mg} / \mathrm{dl}$ in women. This is considered to be the principle cause of gouty arthritis [13].

1. Definition of gouty arthritis: The acute and chronic clinical manifestations caused by the deposition of monosodium urate crystals in articular and extra-articular tissues

2. The greater sUA levels exceed their plasma saturation point, the greater the likelihood of acute gouty arthritic attacks

3. Serum uric acid levels in excess of $10 \mathrm{mg} / \mathrm{dl}$ promote formation of tophaceous deposits that may present as late as 10 years from the initial gouty attack.

\section{Material \& Methods}

We prospectively obtained 41 knee MRI studies of 19 patients with tophaceous gout: 28 at the beginning [3 of them bilateral] and 13 during the follow-up [ 1 of them bilateral] after receiving hypouricenmiante treatment, after obtaining ethical clearance by the ethical committee constituted by the associated SARDAR PATEL MEDICAL COLLEGE, BIKANER.

All the patients were men with a mean age at the first resonance of 56 years and all of them were diagnosed with gout through the direct visualization of Monosodium Urate crystals [MSU] in the synovial fluid of the knees.

The images were obtained in a MRI of $1.5 \mathrm{~T}$ and the following sequences were included:

$$
\begin{aligned}
& \text { - T1 sagittal } \\
& \text { - STIR and T2* coronal }
\end{aligned}
$$




\section{- $\mathrm{T} 2$ and $\mathrm{T} 2 *$ axial}

- T1 STIR after axial and sagittal gadolinium.

After completing the imaging, these were retrieved and evaluated randomly and blindly by two observers who evaluated each study twice, with an interval of 3 months between each evaluation.

The maximum lateral-lateral [LL], anterior-posterior [AP] and cranial-caudal [CC] diameters of each tophus were measured in the sequence in which better it was delimited. Both baseline and follow-up images were used to assess intra- and inter-observer correlation [Figure 1, 2, 3].

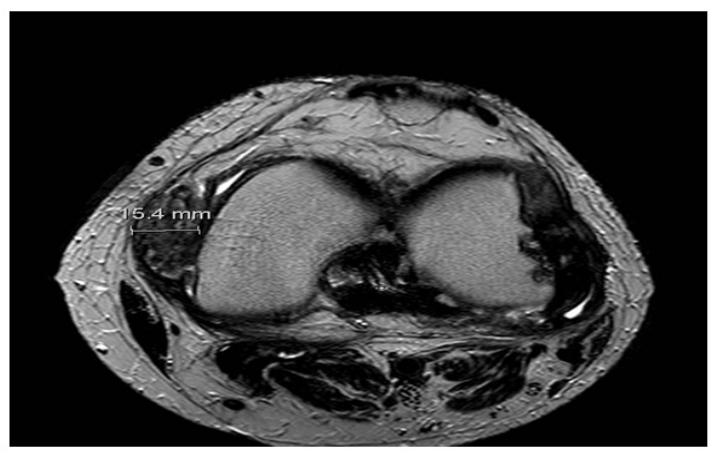

Figure 1:Axial sequence T2. Measurement of the lateral-lateral diameter (LL) of tophis.

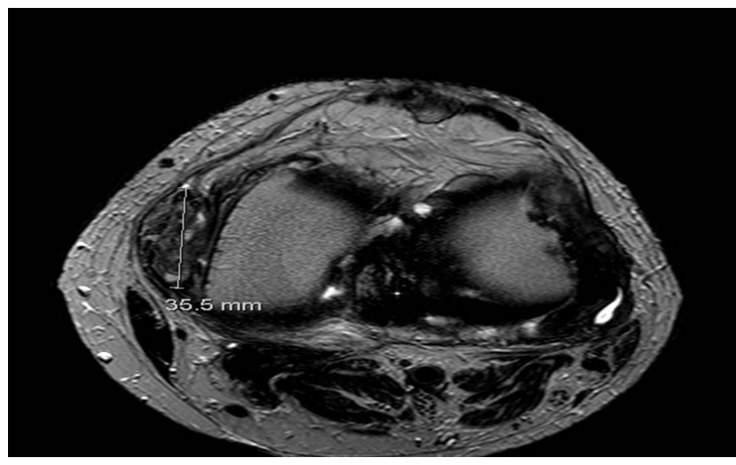

Figure 2: Axial sequence T2. Measurement of the anterior posterior diameter (AP) of tophi.

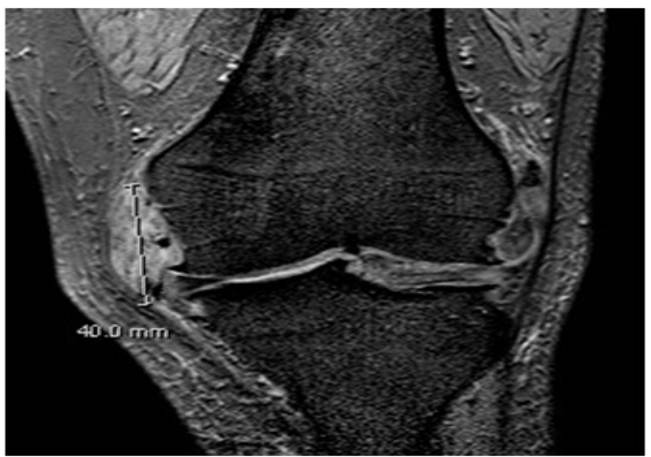

Figure 3: Coronal sequence T2 $*$. Measurement of the craniocaudal diameter (CC) of tophi
The reduction of the tophi was determined according to the changes in the CC, LL and AP diameters and corrected according to the time of exposure to the hypouricemic therapy measured in months.

The minimum detectable change was estimated according to double the standard deviation of the difference of the means of measurements and the effect of size by the Guyat method.

\section{Results}

104 tophi were evaluated with the mean of the maximum diameter of the tophi in LL, AP and CC of 13, 20 and $26 \mathrm{~mm}$ respectively.

The concordance for the detection of tophi was 101/104 tophi [96.7\%].

The interobserver intraclass correlation was 0.96 in LL, 0.92 in AP and 0.92 in CC. [Table 1]

The intraobserver intraclass correlation was $0.98,0.98$ and 0.95, respectively. [Table 1]

The smallest detectable difference was $1.9 \mathrm{~mm}[14 \%], 3.3 \mathrm{~mm}$ [16\%] and 4mm [19\%] for the maximum diameters of the tophi in LL, AP and CC respectively.

A multivariate regression analysis showed that the greatest changes in measurements during follow-up were associated with greater baseline diameters [lateral-lateral diameter] and lower uric acid levels.

Table 1: Summary table of inter- and intra-observer intraclass concordance data.

\begin{tabular}{|c|c|c|c|}
\hline & $\begin{array}{c}\text { Diameter } \\
\text { LL }\end{array}$ & $\begin{array}{c}\text { Diameter } \\
\text { AP }\end{array}$ & $\begin{array}{c}\text { Diameter } \\
\text { CC }\end{array}$ \\
\hline $\begin{array}{c}\text { Interobserver } \\
\text { Intraclass Correlation }\end{array}$ & 0.96 & 0.92 & 0.92 \\
\hline $\begin{array}{c}\text { Intraobserver } \\
\text { Intraclass Correlation }\end{array}$ & 0.98 & 0.98 & 0.95 \\
\hline
\end{tabular}

\section{Conclusion}

The MRI of the knee in patients with tophaceous gout shows good agreement for the detection of tophi and a good intraclass correlation both intra and interobserver for its measurement when considering the maximum diameters.

The smallest detectable differences were sufficient to evaluate the changes in the size of the tophi in the MR follow-up.

The greatest changes in measurements during follow-up were associated with greater baseline diameters [measured in latero-lateral] and lower uric acid levels.

\section{Common manifestations of gout on MRI include: Erosions}

Various types of tophi including calcified or soft tissue predominant tophi and intra-articular, extra-articular or intraosseous predominant locations

Synovitis 


\section{Tenosynovitis}

Bursitis

Effusions

- While the 1st metatarsophalangeal joint is the most commonly involved site for gout, many other joints may manifest gout related abnormalities on MRI including the ankle, knee, and elbow [14].

Differential diagnostic considerations include [among many other entities] rheumatoid arthritis, pseudo gout, psoriatic arthritis and septic arthritis

- $\quad$ MRI can be helpful in helping differentiate these entities from gout

In conclusion, MRI is a valid technique for the detection and monitoring of tophaceous gout, fulfilling the OMERACT outcome criteria for the follow-up of chronic tophaceous gout.

\section{References}

1. Yu J, Chung C, Recht M, Dailiana T, Jurdi R. MR Imaging of tophaceous gout. AJR. 1997;168(2):523-527. doi:10.2214/ajr.168.2.9016240

2. Poop JD, Bid good WD, Edwards LN. Magnetic resonance imaging of tophaceosus gout in the hands and wrists. Semin Arthritis Rheum. 1996; 25(4):282-289.

3. Schumacher HR, Becker MA, Edwards NL, Palmer WE, McDonald $\mathrm{PA}$, Palo W, et al. Magnetic resonance imaging in the quantitative assessment of gouty tophy. Int J Clin Pract. 2006;60(4):408-414. doi:10.1111/j.1368-5031.2006.00853.x

4. Perez-Ruiz F, Dalbeth N, Urresola A, Miguel E, Schlesinger N. Imaging of gout: findings and utility. Arthritis Research and Therapy. 2009;11:232. doi:10.1186/ar2687
5. Perez-F, Naredo E. Imaging modalities and monitoring measures of gout. Curr Opin Rheumatol. 2007;19(2):128-133. doi:10.1097/ BOR.0b013e32801450b7

6. Gentili A. Advanced imaging of gout. Semin Musculoskelet Radiol. 2003;7(3):165-174. doi:10.1055/s-2003-43227

7. Zhang W, Doherty M, Bardin T, V Barskova, P-A Guerne, T L Jansen, et al. European League against Rheumatism recommendations for calcium pyrophosphate deposition. Part I: terminology and diagnosis. Ann Rheum Dis. 2011;70(4):563-570. doi:10.1136/ard.2010.139105

8. Brower AC. Arthritis in black and white. Philadelphia: WB Saunders. 1988

9. Manaster BJ. Handbook of skeletal radiology. 2nd ed. St. Louis: Mosby. 1997

10. Resnick D. Bone and Joint Imaging. 2nd ed. Philadelphia: WB Saunders. nineteen ninety six.

11. Clyde A.Helms, James B. Vogler, David A. Simms, Harry K.Genant. CPPD crystal deposition disease or pseudogout. Radio Graphics 1982;2(1):40-52.

12. Dalbeth N, McQueen F. Use of imaging to evaluate gout and other crystal deposition disorders. Curr Opin Rheumatol. 2009;21(2):124131. doi:10.1097/BOR.0b013e3283257b6c

13. Gary D Wright, Michael Doherty. Calcium pyrophosphate crystal deposition is not always 'wear and tear' or aging. Annals of the Rheumatic Diseases. 1997;56(10):586-588.

14. Goto S, Umehara J, Aizawa T, Kokunun S. Crowned Dens syndrome. J Bone Joint Surg Am. 2007;89(12):2732-2736. doi10.2106/ JBJS.F.01322 